\title{
LA NUEVA PROVINCIA: \\ (RE)POBLAMIENTO DE LOS TERRITORIOS \\ AGRARIOS. CHILE 1982-2002
}

Manuel Canales Cerón y Alejandro I. Canales Cerón 


\section{MANUEL CANALES CERÓN}

Sociólogo de la Universidad de Chile. Doctor en Sociología de la Universidad Complutense. ProfesorInvestigador asociado, Departamento de Sociología, Universidad de Chile.

\section{ALEJANDRO I. CANALES CERÓN}

Economista y demógrafo. Doctor en Ciencias Sociales del Colegio de México. Profesor-Investigador y director del Centro de Estudios de Población, Universidad de Guadalajara. Investigador Nacional, Nivel III; Consejo Nacional de Ciencia y Tecnología, México. 


\section{LA NUEVA PROVINCIA: \\ (RE)POBLAMIENTO DE LOS TERRITORIOS AGRARIOS. CHILE 1982-2002}

\section{INTRODUCCIÓN}

En este ensayo se propone que, en Chile, desde los años 70, en el contexto del desarrollo de la nueva agricultura exportadora, está ocurriendo un repoblamiento de los territorios o zonas agrarias. En particular, se propone que dicho repoblamiento es, ahora y en diferencia a los campos tradicionales, a) predominantemente urbano en el hábitat, y b) "procesador" o industrial en lo productivo.

Se trata de un repoblamiento que no concuerda ni con los esquemas tradicionales de lo que debiera ser el desarrollo rural-urbano, como tampoco con el futuro que hace 50 años se vaticinaba para estos territorios. Al final no ha habido ni un despoblamiento rural (desde los años 60, la población rural en Chile se ha mantenido sin grandes variaciones en los dos millones de personas, mostrando una notable estabilidad, que parece contrastar con la vorágine histórica de estos últimos cincuenta años) y, además, esta población rural, en conjunto con la que vive en las ciudades agrarias, son hoy casi dos veces más que lo que fueron entonces, y, desde hace ya treinta años, vienen creciendo más rápido que las metrópolis.

Así, presentamos nuestra propuesta en cuatro entradas.

La primera, conceptual, discute el nombre de quiénes hablamos. Distingue población rural, población urbano-agraria y población agraria, que resulta de su suma, a las que distingue u opone con la población urbano-metropolitana. Pasa, de este modo, del par categorial rural-urbano al nuevo de agrópolis / metrópolis.

La segunda, empírica, analiza la evolución demográfica chilena entre los censos 1982-2002, identificando el comportamiento específico de las ciudades agrarias y su conexión con la actividad agroindustrial. Se verifica allí que las ciudades de base agraria, en este caso agro-industrial, son las que tienen, en las últimas décadas, el mayor dinamismo demográfico en el conjunto nacional.

La tercera, mostrando el efecto invisibilizador que tiene el uso, en su acepción actual, del par rural-urbano para informar de la estructura socioeconómica de la provincia o el interior agrario. Analizando los datos de pobreza y estratificación social, se verifica que la oposición rural-urbano falla sobre todo por su segundo término, al fundir, confundiendo, las ciudades de base agraria con las urbes metropolitanas, juntando en los conceptos lo que la realidad separa.

En el cuarto, se observa a la población en sus territorios, y se constata la crisis, también, de su representación geográfica, al no estar reconocidas como tales las zonas o territorios agrarios, en ninguna de sus múltiples escalas. La malla regional-comunal, el esquema actualmente predominante, y hasta oficial para pensar y gobernar los territorios, les niega por arriba -la región los excede siempre-y por abajo -la comuna nunca los alcanza-. 


\section{POBLACIÓN RURAL, POBLACIÓN AGRARIA: LA CUESTIÓN DEL NOMBRE}

Hasta los años 60, incluso algo después, la gente del campo era agraria y rural, casi en sinonimia; los trabajadores agrícolas vivían en poblamientos rurales, y al conjunto se llamaba, sin más, el campo. Y así era, pues se convenían, como en la geografía humana del fundo y la hacienda, una producción agraria tradicional con un habitar in situ, en la conjunción de la casa-predio agrícola que define el habitar rural.

A partir de los 70, la transformación de la actividad agraria hacia su forma actual, capitalista en su racionalidad social, y agro-industrial en su racionalidad productiva, ha conllevado transformaciones igualmente radicales en la composición demográfica de las geografías donde predomina.

Ahora, en la nueva pauta, lo agrario y lo rural ya no son intersección plena de la imagen tradicional. Según se mostrará, en lo esencial, ya no todo lo agrario es rural.

Lo que ocurrió fue lo siguiente: la nueva agricultura fue esencialmente agroindustrial, mientras que la anterior era sustantivamente agrario-primaria. Si a esta última convenía un modo de poblar rural, a la nueva pauta productiva acomoda mejor un poblamiento urbano (Canales A.I., 1996).

La población que vivía en la ruralidad -esto es, en aldeas y caseríos donde la presencia de la pequeña agricultura o agricultura familiar- marca el paisaje, continúa allí, sin crecer ni decrecer. Sin embargo, va a ocurrir que el otro componente de la geografía humana base de los campos, la ciudad agraria, va a experimentar un crecimiento demográfico notable. Las ciudades agrarias, en treinta años, logran hacerse predominantes respecto de lo rural en sus territorios -se urbaniza el campo- y también llevar la delantera del crecimiento poblacional nacional -Chile se re-agrariza, al menos demográficamente-.

En lo que sigue, discutimos brevemente los intentos conceptuales que buscan salvar la distancia entre los campos nuevos ${ }^{1}$ y los nombres con que bien se refirió a los campos tradicionales ${ }^{2}$.

Discernimos dos caminos para este ajuste conceptual:

a) O se intenta re-significar lo que fuese lo rural, para, con esa renovación, referir lo que cambió del objeto, pero manteniendo el nombre, como si lo acontecido fuese un cambio de lo rural, que, sin embargo permanecería como un núcleo estable del asunto. Son múltiples modos de una neo-ruralidad.

b) O proponiendo una re-categorización basada, esta vez, no en el patrón de hábitat, sino en el fundamento socio-productivo de los distintos territorios, esto es, desde un enfoque de la geografía socio-económica que distingue y permite conceptuar los agro-territorios.

1. Extraemos la noción de una asociación de productores de tomate, en el Valle Ventral, que nombró así su intento de nueva agricultura a inicios de los 90.

2. Es el desasosiego de la sociología rural, pero también debiera serlo, como se indica al final, de los geógrafos en general. 


\section{NUEVA RURALIDAD}

Así se nombró, en el sur europeo, pero también en Estados Unidos, a una nueva forma de entender y habitar la ruralidad. La forma de una crisis final del mundo agrario-rural, que despuebla el campo, cuyas casas son recuperadas y refaccionadas para ser habitadas ahora en un régimen no agro-productivo, por profesionales o en general personas de posiciones de clases superior a los antiguos habitantes, es la que sostiene la verosimilitud de lo nuevo rural: nuevo habitante, nueva lógica, en fin, nueva ecología humana respecto de la precedente periclitada. Por ello, un indicador clave de nueva ruralidad terminó siendo el aumento de ingresos "extra-prediales", o, sin más, extra agrarios de los habitantes; señal inequívoca de la decadencia de la actividad agraria y el des-anclaje final de lo rural y lo agrario. Eso era, en fin, la nueva ruralidad: la ruralidad por definición no agraria (Nogue, 1988; Kay, 2009)3.

Algo de eso hay también en nuestra sociedad; las parcelas de agrado, y la reconexión de los pueblos rurales a sus ciudades vecinas, han permitido una complejización del fenómeno rural igualmente interesante. Sin embargo, lo esencial esta en otro lado y en un sentido opuesto: justo en la época en que España despoblaba sus ruralidades por decrecimiento agrario, en Chile comenzaba el repoblamiento de las ciudades interiores por el desarrollo de la agroindustria vinculada al nuevo modelo agroexportador. Más que nueva ruralidad, aquí, nueva agricultura. Si allí ya no todo lo rural es agrario -pues ahora predomina la pauta residencial, no productiva, en el hábitat rural-, en Chile, según ya indicamos y esperamos demostrar, ya no todo lo agrario es rural -pues ahora predomina la pauta agroindustrial y su forma urbanizada de poblamiento (PNUD Chile, 2008)_.

Por eso es que el uso no discutido de la noción de nueva ruralidad importa un equívoco grave: pasa que lo nuevo allí es opuesto a lo nuevo aquí; lo que ocurre en Chile no está centrado en la aventura de la ruralidad ${ }^{4}$ como en la suerte y destino de las urbes que van a crecer demográficamente con la nueva agricultura.

\section{CONTINUO RURAL-URBANO}

Otro modo de superar la distinción categorial rural-urbano es por la vía de relajar la oposición entre los términos y redefinirlos en un continuo, tal que ya no designan polos

3. Para una nota crítica, puede verse el texto de Gómez, S., La nueva ruralidad. ¿Qué tan nueva? (Revisión bibliográfica, un intento por definir su alcance y propuesta conceptual para investigaciones), 2da. edición ampliada, Santiago de Chile: Grupo de Investigaciones Agrarias y Universidad Academia de Humanismo Cristiano, 2008; y Gómez, S., "Reflexiones sobre la nueva ruralidad en América Latina", en Revista paraguaya de sociología, № 138, Centro Paraguayo de Estudios Sociológicos, 2011.

4. Reconocido es por lo demás que la ruralidad actual chilena es nueva también, como todo lo que cambia continuamente, así, urbano o rural, fuera del prejuicio que imagina que lo rural actual pudiera ser en algún sentido como lo tradicional. Hay una ruralidad moderna, como hubo ciudades tradicionales. Lo rural y lo urbano pueden ser cambiantes -como ahora- o estables -como lo fueron, ambos, durante siglos (en Chile) y milenios-. 
sino una gradación que admite múltiples modos o valores transicionales (Rodríguez, Saborío y Candia, 2011). El concepto tiene la eficacia de liberarnos del prejuicio sobre una ruralidad estancada y opuesta en todo al mundo urbano. Pero lo hace, según nuestro juicio, con un costo muy alto, al disolver lo que sigue siendo una diferencia estructurante de los territorios, particularmente los agrarios, que debe ser reconocida y tratada en su polaridad conceptual.

A fin de cuentas, rur-urbano, por ejemplo, es solo una (des)categorización o tachadura de la oposición, que disuelve un deslinde conceptual, pero no traza una distinción que la reemplace. Y es más, borra demasiado rápido lo que por otra parte permanece -la población rural, que no por modernizada se transforma en urbana- ${ }^{5}$.

\section{TERRITORIOS RURALES}

Una tercera forma que nos interesa enunciar para su contraste es el planteamiento de los territorios rurales, y más recientemente, de las ciudades rurales. La introducción del concepto "territorio", y la imagen de "ciudad rural" requieren una reflexión aparte cada una:

a) Territorios rurales (Apey y Barril, 2006; Berdegué y Jara et al., 201la.): avanza un paso más allá de la analítica "urbanística" o de hábitat para formularse en un lenguaje "ecológico" o de territorialidad. Es la toma de razón del fondo físico-social de la vida rural, que la inserta en un paisaje constitucional. La pista "geográfica" o territorial, sin embargo, queda cerrada con el predominio de la distinción rural-urbana: al llamarlos rurales, los territorios quedan trazados según su patrón de habitar, y no como aquí proponemos, según su patrón productivo.

Desde nuestra perspectiva, los territorios en referencia no quedan bien descritos como rurales; por lo pronto, en su interior hay urbes, y aun más, cada vez hay más urbe: ¿cómo podría una urbe contenerse en un territorio rural?

El concepto de ciudad rural (Berdegué y Jara et al., 2011b) con que se intenta resolver el problema no alcanza a tampoco y por lo mismo: si la ciudad es rural, ¿cómo nombrar y definir a los poblamientos del tipo aldeas, caseríos y otras formas clásicas y persistentemente rurales que les circundan y con quienes tiene una relación simbiótica decisiva? En realidad las ciudades de las que se habla no han sido nunca, ni menos lo son ahora, rurales, pues fueron diseñadas, fundadas y habitadas desde su origen como tales, para estructurarse y funcionar como urbes.

5. Su déficit conceptual no le resta, sin embargo, potencia ideológica: en la encuesta del PNUD, Informe de desarrollo humano en Chile rural, 2008, más de un tercio de los encuestados -en una muestra que cubrió, prácticamente, todo el territorio agrario chileno- se reconocieron en esa categoría, y la prefirieron a rural o a urbano. Sea lo que fuere su significado, rur-urbano al menos marca la crisis de los conceptos previos y sus nombres. 


\section{TERRITORIOS Y POBLACIÓN AGRARIA}

Desde nuestra perspectiva, la solución conceptual para dar cuenta del cambio en el objeto, requiere atender no solo al hábitat rural/urbano, sino al fundamento productivo del territorio: lo que define al campo, antes y ahora, es el predominio de la actividad agraria, la misma que puede realizarse con un patrón de poblamiento casi exclusivamente rural (producción agraria primaria) o con un patrón de poblamiento a) rural y b) agro urbano (producción agraria primaria y agroindustria) (Canales M., 1989, 2008).

Puede definirse, en síntesis, como el objeto de este ensayo, a la población agraria: habitantes de territorios en los que la actividad económica predominante esté vinculada a la actividad piscisilvoagropecuaria ${ }^{6}$, ya sea primaria, agro-industrial, o de servicios. Esta población, respecto al hábitat, contiene un subconjunto rural y un subconjunto urbano. No puede por eso llamársele "rural" sin excluir al segundo ${ }^{7}$.

Población agraria, como concepto, resulta del siguiente esquema conceptual: transformamos el par "rural-urbano" en el par "agrario-metropolitano", combinando un eje semántico de hábitat con un eje semántico de actividad productiva".

\section{Gráfico 1 \\ RURAL-URBANO / AGRARIO-METROPOLITANO}

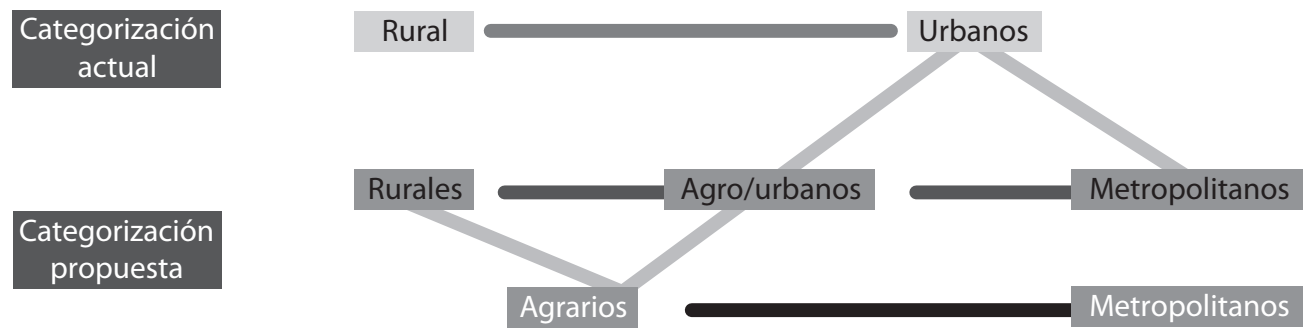

Fuente: Elaboración propia.

Así, en lo esencial, se propone diferenciar dentro de la categoría urbana dos tipos estructurales y opuestos: una forma urbana-metropolitana, y una forma urbana-agraria. Nuestra propuesta es que a) las ciudades agrarias son distintas de las ciudades metropolitanas, y que b) se parecen a la población rural, con la que forman, en conjunto, c) la población agraria -habitante/productor- de los territorios agrarios.

6. Es la noción en uso creciente, agregando la pesca, los bosques y el ganado junto con la agricultura en su sentido estricto.

7. Pero tampoco puede llamársele, sin más, urbano a su otro componente, pues entonces borra a su diferencia con la ciudad metropolitana, y queda indistinta en la noción general, que por la connotación de aquella, la aplana.

8. Este planteamiento puede verse en detalle en Canales, M., Hernández, C., "Del fundo al Mundo. Cachapoal, un caso de globalización agropolitana", Zona Abierta, Venezuela, 2011. También en Canales, M., Hernández, C., "Geografía Humana de la nueva agricultura", "Nueva agricultura, territorio y sociedad. Apuntes sud-americanos", en Revista paraguaya de sociología, N 138, 2011. 
Formulados ya los términos de nuestra observación, los haremos dialogar con los números.

\section{NUEVOS NÚMEROS, NUEVOS NOMBRES}

Vamos a presentar una prueba empírica, en el sentido más básico de pre-conceptual, de a) la existencia de un (re)poblamiento agrario, y b) del modo agro-urbano y agro-industrial de este repoblamiento.

Para ello, vamos a analizar dos cuadros: el primero separa cinco tipos de poblamiento según tamaño en el año 1982, e informa de sus respectivas dinámicas demográficas hasta 2002; el segundo, refiriendo el mismo conjunto de poblamientos, informa de sus respectivas dinámicas productivas. El análisis conjunto debiera probar -o refutar- la hipótesis del repoblamiento agrario aquí esbozada.

\section{DINÁMICAS DEMOGRÁFICAS}

\section{Gráfico 2}

CHILE 1982-2002. DINÁMICA DEMOGRÁFICA DE CENTROS POBLACIONALES, SEGÚN SU TAMAÑO INICIAL
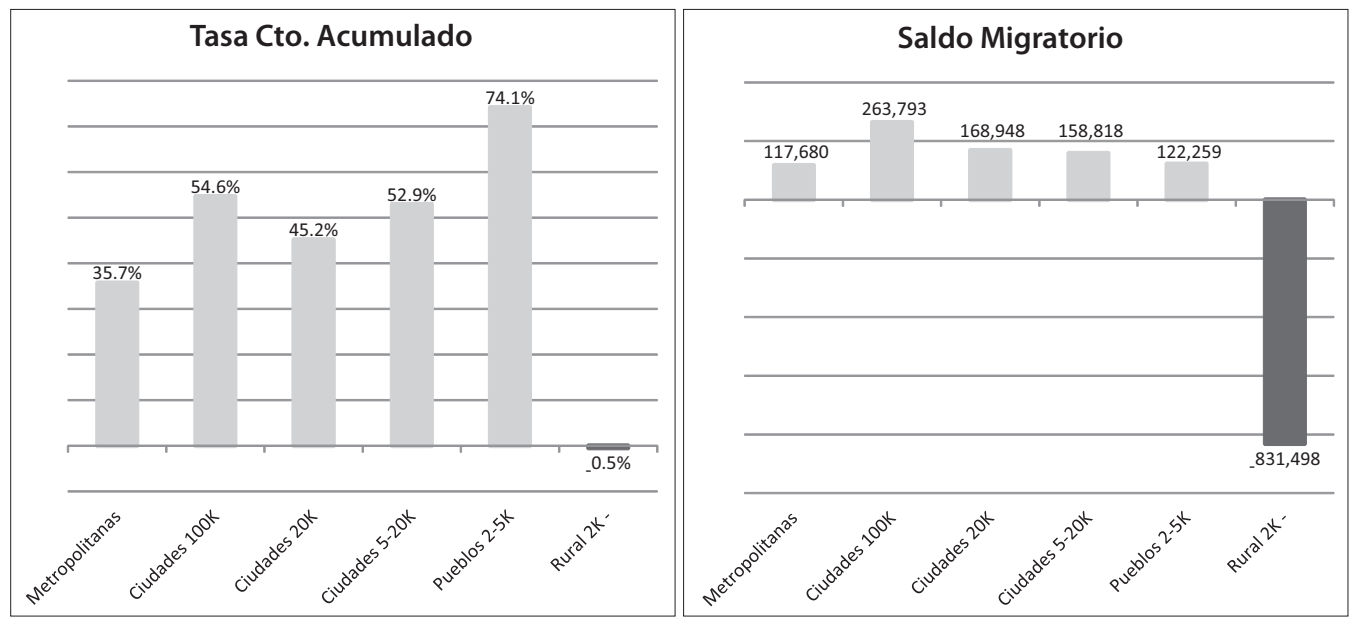

Fuentes: Elaboración propia con base en datos censales.

Los datos demográficos nos permiten diferenciar cuatro pautas de crecimiento según el tamaño de las localidades, a saber:

1. En el extremo de alta densidad, las metrópolis,

2. En el extremo de baja densidad, la población rural; 
3. Entre ambas, pueden distinguirse las ciudades intermedias, que tenían entre 5.000 y cien mil habitantes al inicio del ciclo,

4. Por último, la trayectoria singular de los pueblos no rurales, que tenían entonces menos de cinco mil habitantes.

Así, lo que los urbanistas en general denominan metrópolis, ciudades intermedias, pueblos, y zonas rurales, quedan reflejados, cada uno, con su pauta propia de crecimiento poblacional. Conviene verles una a una, antes del análisis siguiente, en que se les asocia con la dinámica de la actividad productiva (empleo).

Solo lo rural no crece, aunque tampoco decrece. Con todo, según se observa en la imagen al costado derecho, tiene un saldo migratorio negativo de más de 800.000 personas, manteniendo así la pauta histórica que venía mostrando desde los años 40 o 50. Es todavía la emigración de todo el crecimiento vegetativo, con mantención de masa demográfica. Con todo, la cuestión es que aquella migración ya no es hacia la metrópolis, sino a las ciudades intermedias y pueblos vecinos. Por decirlo de otro modo, es una población que deja de ser rural, pero que se queda en su territorio o zona, alimentando ahora a las ciudades del interior, y aun más a los pueblos contiguos, como antes había ocurrido con las metrópolis. Es la nueva forma de la migración rural, ahora "intra-zonal" y, por ello, según se muestra en el apartado siguiente, intra-agraria. Así, pierde sentido la noción cristalizada de "migración campo-ciudad": se trata ahora de un movimiento al interior del campo, desde sus zonas rurales a sus zonas urbanas.

Así, por primera vez, y de modo imprevisto, las ciudades intermedias son las que recogen el excedente restante del mundo rural y retienen el suyo propio, de forma que muestran el dinamismo acelerado que indican los cuadros y que adelanta al ritmo de las metrópolis. Dicho de otro modo, en estos veinte años se constata una detención relativa de la concentración metropolitana de la población y una tendencia a un reequilibrio pluri-centrado en cientos de ciudades intermedias.

Nota aparte requieren los pueblos, que crecen más que todos los otros tipos. Es una caso aparte, pues está contiguo de quienes menos crecen -la ruralidad-, y sin embargo crecen más que las ciudades intermedias y, por cierto, que las metrópolis 9 .

Observando la situación en conjunto, puede dudarse con base firme, estimamos, del dato general del "crecimiento urbano" y de la hipótesis complementaria del despoblamiento rural. No es lo urbano en general lo que crece, sino ciertas urbes, y precisa y sorprendentemente, no las metropolitanas. Y del despoblamiento rural, por lo menos en general y hasta el 2002, no hay noticias ${ }^{10}$.

Cabe entonces la pregunta por el fundamento productivo de estas dinámicas: ien qué se diferencian, productivamente, la metrópolis de las llamadas ciudades intermedias?

9. Algo decisivo -y fino- en la reconfiguración de las geografías humanas agrarias se juega en este dato, pero carecemos de estudios que lo informen.

10. En rigor, sí hay datos, pero cuando el análisis se especializa según macro-zonas, que permite diferenciar casos de crecimiento y casos de decrecimiento. Con todo, el dato global es lo indicado. 


\section{DINÁMICAS PRODUCTIVAS}

El concepto de ciudad intermedia es extremadamente limitado en sus alcances semánticos y referenciales; de hecho, es solo una definición "transicional" que dice lo que no es - ni grande, ni pequeña-, pero en nada alude a lo que la constituye ${ }^{11}$. Poco más dice el concepto. Aquí mostraremos que lo que las define no es su medianía, sino algo bastante más determinante: su inserción en la división global del trabajo.

En el cuadro siguiente se muestra la dinámica del empleo agroindustrial según las mismas configuraciones por tamaño.

\section{Gráfico 3}

CHILE 1982-2002. CRECIMIENTO DE LA POBLACIÓN OCUPADA EN EL SECTOR AGROINDUSTRIAL SEGÚN TIPO DE LOCALIDAD

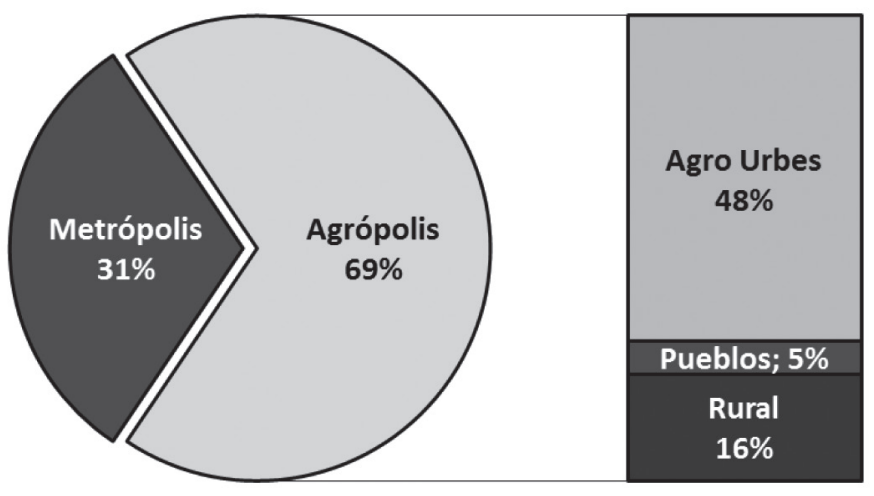

Fuente: Elaboración propia con base en datos censales.

La diferencia esencial entre las metrópolis y las ciudades intermedias radica en el hecho de que en las segundas se ha concentrado el crecimiento agroindustrial. Son, por decirlo sin más, la pauta habitacional o residencial del nuevo capitalismo agrario, y es por esta razón, que las determina, que cabe llamarles ciudades agrarias ${ }^{12}$.

Lo que ocurre es que el nuevo empleo agrario ha sido esencialmente secundario, y conviene a esa forma su fijación urbana, como a la forma tradicional primaria convenía el afincamiento, inquilinato o cualquiera otra pauta habitacional rural.

11. Y así, describen ciudades que dejaron de ser pequeñas pues crecieron, o no alcanzan a ser metrópolis pues les falta seguir haciéndolo. Subyace el preconcepto que entiende que toda ciudad es una metrópolis en potencia; olvida, así, que las ciudades existieron por siglos y hasta por milenios, sin que existiera idea alguna de metrópolis. En suma, la forma general de ciudad, al menos por historia, debieran ser las ciudades "intermedias", que aquí llamaremos agrarias, y las metrópolis en solo su forma aparte e hipertrofiada (si se quiere, gran ciudad).

12. O neo agrarias, si se quiere, para separarlas del antiguo campo al que servían, entonces, como ciudades de servicios. 
De paso, queda señalado un hecho significativo: la tercerización de la sociedad y economía chilena, que alcanzan su cúspide en las metrópolis, y que, como dinámica, se percibe también en todos los poblamientos, no logra congregar, por sí misma, crecimiento demográfico. Lo que hace la diferencia en el dinamismo demográfico es la presencia o ausencia de agroindustria. La industria no agraria destaca por su ausencia, y la agricultura primaria, como la actividad terciaria, no logra retener o atraer más población. Solo la agroindustria muestra esta potencia y revela un aspecto profundo del modelo de desarrollo: los "servicios" de que se habla en Chile están fuera del proceso productivo, y se reducen en lo esencial a la zona reproductiva. Por eso es que solo los mercados laborales productivos secundarios, en Chile asociados a la agricultura, generan dinámicas demográficas poderosas ${ }^{13}$.

\section{NUEVOS NOMBRES, NUEVOS NÚMEROS}

En esta apartado comparamos el rendimiento informacional del esquema rural-urbano con el esquema, aquí propuesto, de agrópolis/metrópolis, analizando los datos de pobreza y de estratificación. Pretendemos mostrar que el segundo distingue y describe lo que el primero borra.

\section{Niveles de pobreza}

Puede verse el cuadro inicial, observando la distribución de la pobreza según la distinción clásica.

\section{Gráfico 4}

CHILE 2009. NIVEL DE POBREZA E INDIGENCIA RURAL-URBANA

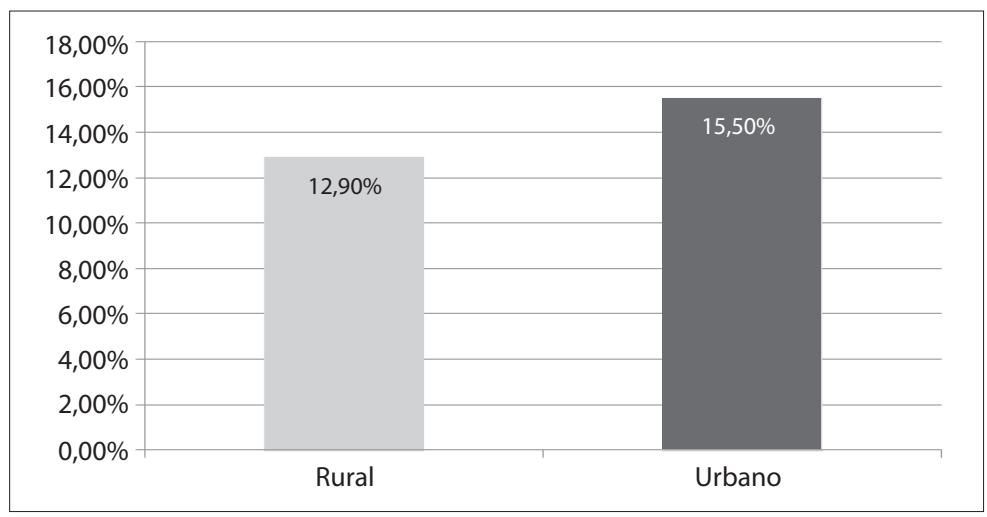

Fuente: Elaboración propia en base a CASEN 2009.

13. Es evidente que la minería es el otro configurador potente de territorialidad. Sin embargo, su masa demográfica se registra en otra escala a la que se usa en estos análisis. 
El resultado señala el fin de la brecha histórica, incluso con una sorprendente -aunque suave- inversión del asunto. Así, la pobreza sería ahora crecientemente un hecho urbano, como antes fue un rasgo del estereotipo rural.

Vamos a observar ahora, en los dos cuadros siguientes, el uso de la re-categorización aquí propuesta, distinguiendo entre los urbanos a las ciudades agrarias de las ciudades metropolitanas.

\section{Gráfico 5}

CHILE 2009. NIVEL DE POBREZA SEGÚN TIPO DE LOCALIDAD

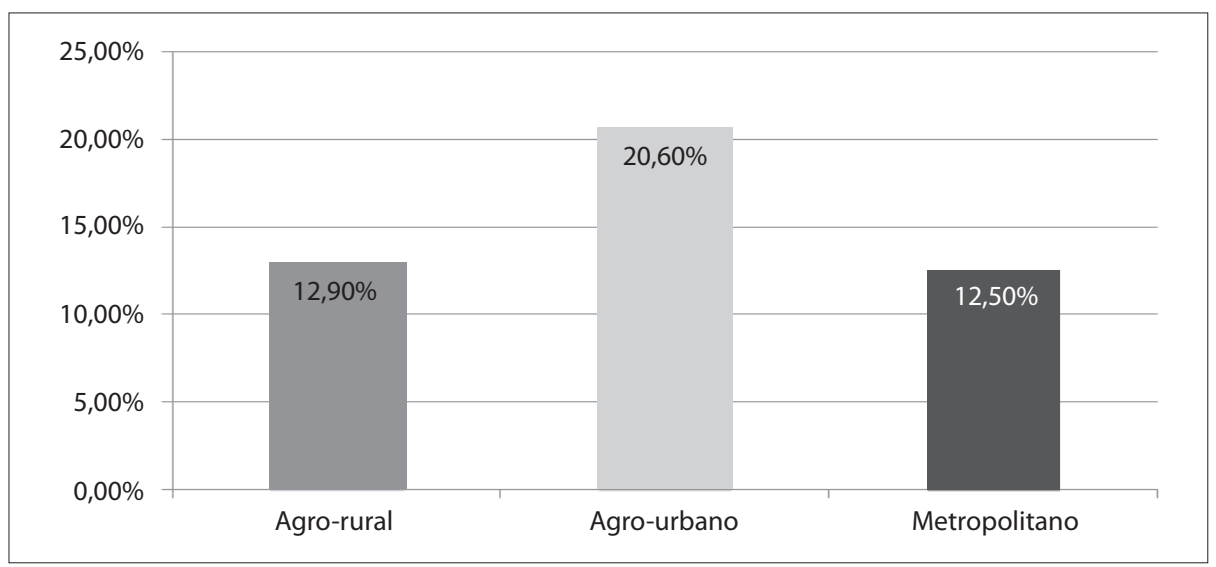

Fuente: Elaboración propia, en base a datos CASEN 2009.

Como puede verse, el conjunto urbano en realidad eran dos, opuestos o polares. El componente urbano metropolitano mostraba un nivel de pobreza bajo el promedio, y el componente urbano-agrario mostraba un indicador sobre el promedio. Entonces, urbano solo refiere un efecto estadístico que aplana, borrando, la diferencia que existe ahora, no ya entre lo rural y lo urbano, sino entre lo agrario-urbano y lo urbano metropolitano.

El cuadro inicial, que comparaba niveles de pobreza entre la población urbana y la población rural, se revela como una imagen que deja en la sombra la concentración de la pobreza en las ciudades agrarias, y por lo mismo, la mantención de una pobreza agraria por arriba de la metropolitana. De paso, demuestra que en las metrópolis sigue habiendo, como siempre, menos pobreza que en la provincia. 
Gráfico 6

CHILE 2009. POBREZA SEGÚN AGRÓPOLIS/METRÓPOLIS

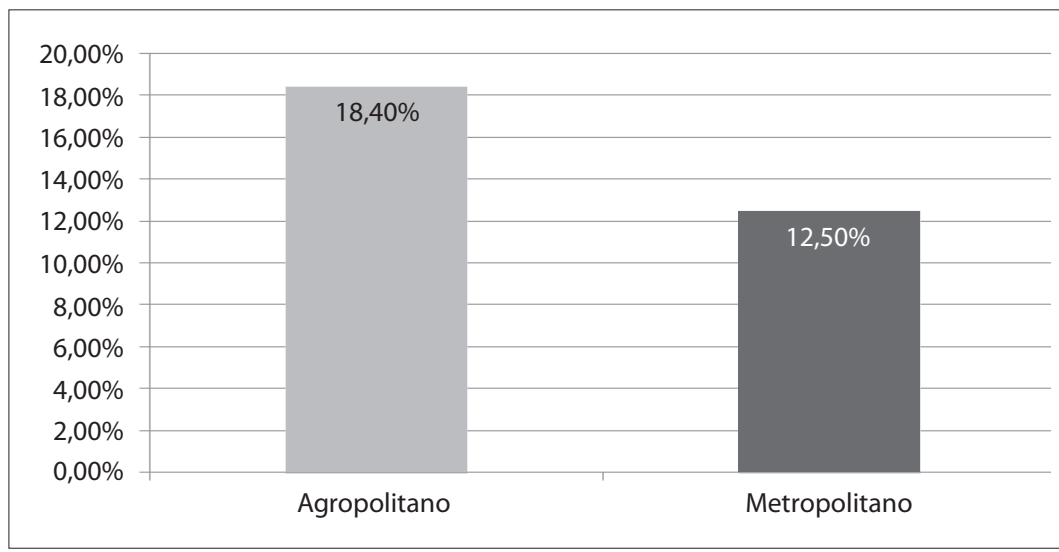

Fuente: Elaboración propia en base a datos CASEN 2009.

\section{ESTRATIFICACIÓN COMPARADA}

El mismo ejercicio lo realizamos ahora con la variable estratificación socioeconómica. Con ello mostraremos cómo la población resulta sociológicamente deformada cuando se le analiza con el esquema rural-urbano en su forma general; mostraremos que, al igual que en el análisis anterior, urbano nombra un promedio forzado, pues no hay continuo sino dos polos dentro del conjunto reunido como tal. Al final de la secuencia, los números ya no dicen nada consistente (o al menos mayormente consistente con otros conceptos) y adherente (a los hechos o fenómenos que se quería y creía medir de esa forma).

Para medir la estratificación utilizamos el siguiente recurso: tomando como tabla de comparación los deciles de ingresos de la población chilena como conjunto, observamos la forma especifica que resulta para cada uno de los sub-conjuntos poblacionales en análisis (urbanos, rurales; metropolitanos, agro urbanos, agrarios).

Así, cada conjunto poblacional revela la forma de su estratificación social; acusará en la tabla promedio nacional, aquellos en los que está por encima y por debajo, y en cuánto, del promedio nacional ${ }^{14}$.

Puede observarse en primer término la información con los conceptos tradicionales:

14. Es, en síntesis, una representación gráfica de los ingresos de los habitantes de cada población, en comparación con el promedio nacional. Si no hubiera diferencia alguna en la estratificación social, entre las distintas poblaciones que distinguimos en el conjunto poblacional chileno, el resultado sería que todas tendrían la misma forma base de aquel conjunto universo. Toda desviación de esa base es orden, o, lo que es lo mismo, información sobre la estructura socioeconómica de la población. 


\section{Gráfico 7}

CHILE 2009. ESTRATIFICACIÓN POR DECILES DE INGRESO SEGÚN RURAL-URBANO

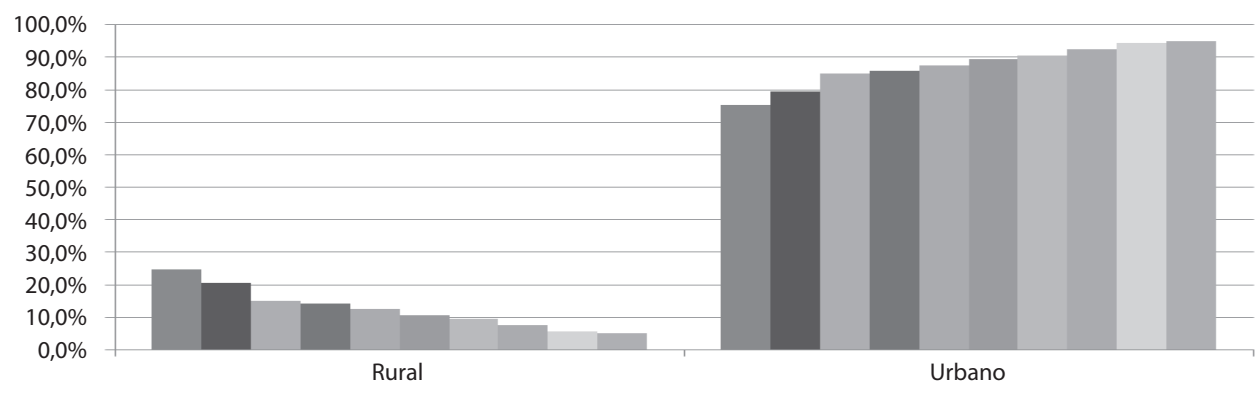

Fuente: Elaboración propia en base a datos CASEN 2009.

Se constata, por un lado, el orden decreciente en la población rural, según se asciende en los ingresos. Dicho de otro modo, la población rural se concentra en los deciles inferiores, aunque no necesariamente sobreconcentrada en los primeros. Por su lado, la población urbana parece, en cambio, tender a asemejarse al formato nacional o forma plana.

Veamos ahora el cuadro siguiente, introduciendo la diferencia agrario-urbano.

\section{Gráfico 8}

CHILE 2009. ESTRATIFICACIÓN EN DECILES DE INGRESOS, SEGÚN RURALIDAD, AGRO-URBES Y URBES METROPOLITANAS

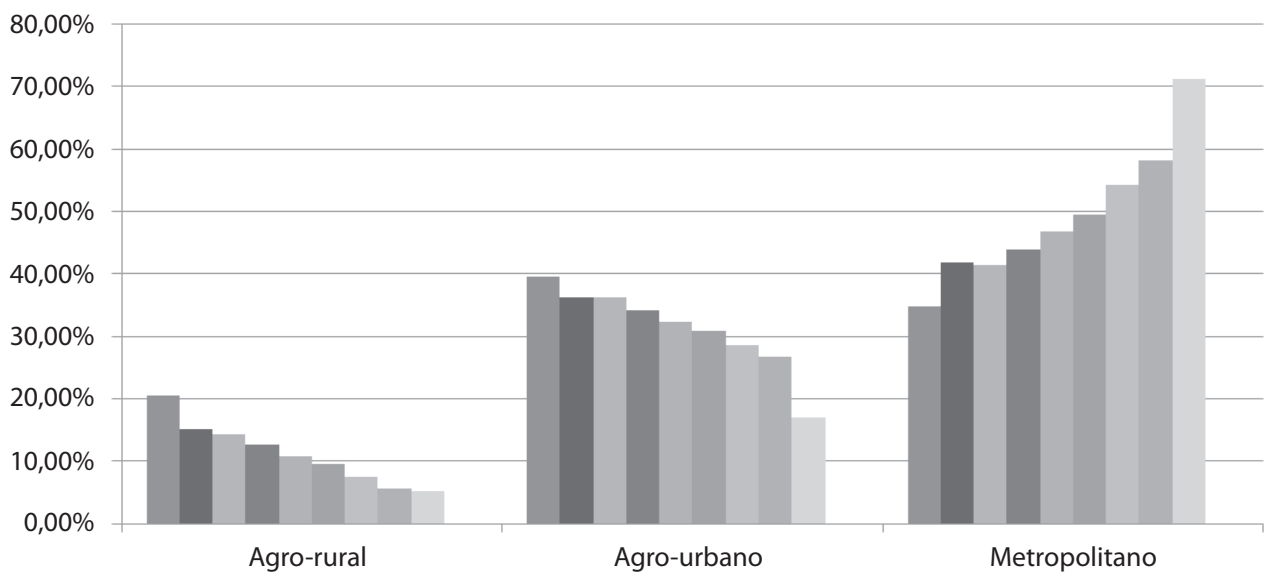

Fuente: Elaboración propia en base a datos CASEN 2009.

El cuadro es más ordenado, esto es, tiene más estructura: a) Lo rural mantiene su orden y sentido, b) lo agro-urbano resulta ordenado también, y en el mismo sentido 
que la población rural, con el que forma, por eso, conjunto estadístico, y c) lo urbano metropolitano también gana en forma, y precisamente en la opuesta o complementaria a la de rurales y agro-urbanos.

Así re-categorizados aparece mayor orden, pues al descomponer el espectro urbano en sus formas agrarias y metropolitanas se posibilita que una y otra perfilen sus propias y opuestas contexturas. Nuevamente se demuestra que lo que nombramos como urbano no se constata en los datos, y que neutraliza una diferencia fundamental que opone en su interior a una forma agraria con una forma metropolitana. De hecho, como se aprecia en el cuadro siguiente, hay más orden en los datos, lo cual refleja alguna relación entre los hechos si en vez de rural/urbano utilizamos el par agrópolis/metrópolis.

\section{Gráfico 9}

CHILE 2009. ESTRATIFICACIÓN EN DECILES DE INGRESO, SEGÚN AGRÓPOLIS/METRÓPOLIS
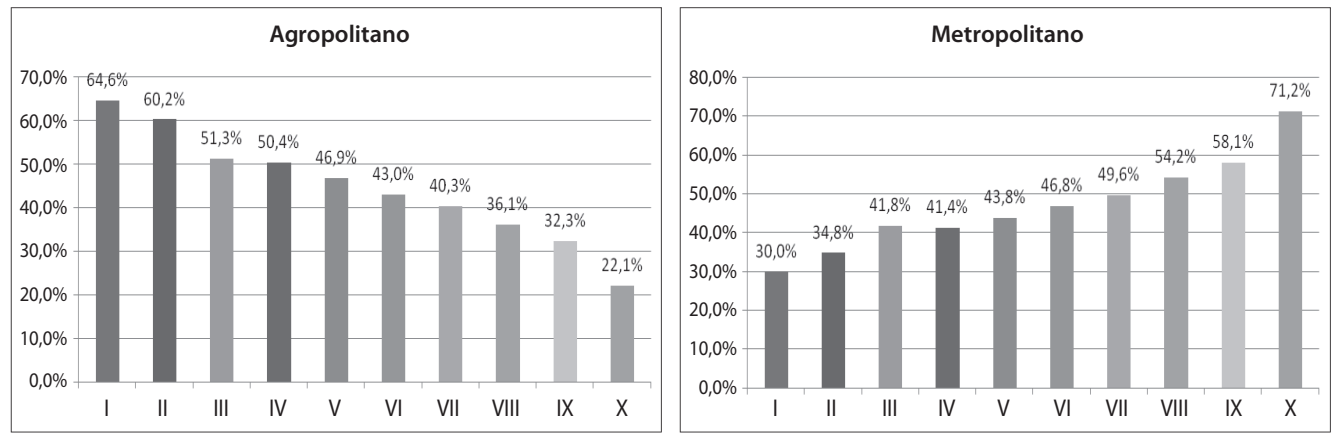

Fuente: Elaboración propia en base a datos CASEN 2009.

No hay ya líneas planas, todo es orden: el horizonte de expectativas de una persona en zonas agrarias se ve limitado al horizonte popular, pues las clases medias están fuera, concentradas en las comunas respectivas de las metrópolis ${ }^{15}$.

\section{REPOBLAMIENTO AGRARIO Y TERRITORIO: LOS MAPAS QUE FALTAN}

El repoblamiento agrario aquí informado, así como escapa de los conceptos abstractos de hábitat rural/urbano, no calza tampoco con los mapas con que se toma nota administrativa y política de los territorios.

15. Es, por decirlo de otro modo, como si la forma socioeconómica de los territorios agrarios se correspondiera con la de las zonas populares de la metrópolis. Es la forma del nuevo pueblo agrario, que viene a juntarse con las formas históricas que permanecen en los pequeños agricultores o, en general, agricultores no capitalistas. 
Como se sabe, los deslindes activos están definidos en las 15 regiones y las 346 comunas. La información y la intervención están organizadas en esa representación de la espacialidad ${ }^{16}$. El punto es que ni regiones ni comunas se corresponden, en general, con territorios agrarios. Nombran una ecología humana, o la suponen, que no es nunca la que corresponde a un valle o una cuenca, como lo son, de modo característico, los territorios agrarios. En los hechos, los territorios agrarios tienden a coincidir con espacialidades inter-comunales, provinciales y macro-zonales. Habitualmente se extienden como un conjunto de comunas contiguas, insertas en un mismo paisaje físico/social, cuya población lo habita y trabaja formando una red de producción y un mundo de vida que enlaza, sistémica e intersubjetivamente, con su historia y su agenda propia, al pueblo o gentes de allí. Son comarcas que alcanzan hasta los deslindes del paisaje, por ejemplo provincial o inter-comunal, difícilmente regional, y que han sido remarcadas como tales por la globalización.

Las comunas quedan estrechas, pues refieren a micro zonas agrarias que forman parte directa de una zona que las determina en parte importante. Así, observado desde la comuna, el territorio agrario se desdibuja, poniéndose en su lugar la imagen abstracta de una "comuna-municipio", con su ciudad cabecera y sus campos exteriores. Observado de nuevo, ahora como territorio agrario, a escala valle o micro cuenca, no hay tal interior-urbano y exterior-agrario; en vez, todo el conjunto inter-comunal se revela como una red de poblamientos de distinta densidad en medio de los campos que los sostienen ${ }^{17}$.

Las regiones se exceden, pues refieren a conjuntos de difícil coherencia física y social. Así, habitualmente partidas por la Cordillera de la Costa, se superponen forzadamente al relieve oro e hidrográfico y sus consecuencias climáticas y edafológicas, reuniendo, a fuerza de decreto administrativo, pueblos y ciudades que no tiene entre sí las relaciones supuestas. Por lo mismo es que las regiones actuales no coinciden habitualmente con territorio real alguno, y en cualquier caso, no con los territorios agrarios ${ }^{18}$.

Puede considerarse a su vez el otro anillo territorial, las antiguas macro zonas -Norte Grande, Norte Chico, Valle Central, Secano Costero, Secano Interior, Centro Sur, Sur Mapuche, Sur, Sur Austral- con que se dibujó una idea de país plural; también estas fueron borradas por la lienza lisa de las regiones actuales. Ocurre que aquellas mantienen, en

16. Hemos tratado esto en profundidad en Vega, J.E., Canales, M., y Órdenes, S., Índice de equidad territorial, SUBDERE, 2007, (inédito). Allí planteamos que los territorios vividos o funcionales se despliegan en inter-comunas y provincias, y no como regiones o comunas. Una comprobación notable de este enfoque está en el reciente estudio, ya citado, de RIMISP sobre territorios funcionales.

17. El clásico estudio Valle de Putaendo. Estudio de estructura agraria de Rafael Barahona y equipo, en los años 50, sigue siendo inspirador, pues señala lo central: el objeto no es lo rural, sino el valle, esto es, el territorio agrario.

18. Cuesta entender la porfía administrativa con la regionalización. El esquema pierde incluso seriedad básica cuando comienzan a desordenarse los números romanos y, por lo mismo, sea cada vez más difícil dominar siquiera la nomenclatura. Por lo demás, se sabe de intentos continuos de antiguas provincias de volver a su sitial topológico y toponímico (así Nuble, San Felipe, Los Andes, o la búsqueda en Maipo, Talagante y Melipilla), como lo reconquistado ya por Valdivia. 
lo básico, sus perfiles y especificidades agrarias. Incluso más, al igual que lo que ocurrió a las provincias y las inter-comunas, la globalización como especialización de paisajes productivos, tiende a remarcarlas.

Así, los tres modos en que el agro, antiguo y nuevo, hace territorio y fija población, están negados: en la división administrativa vigente, ni inter-comunales, ni provincias, ni macro-zonas existen de modo relevante. La consecuencia es evidente: los territorios que no se visualizan, no se gobiernan, o lo que es lo mismo, quedan expuestos a las tendencias entrópicas que los arriesgan en su consistencia.

\section{REFLEXIONES DE SALIDA}

El sueño moderno de Chile, aun antes del mito actual, fue dejar atrás la agricultura. Así lo pactaron en los 30, cuando dejaron los campos, y sobre todo a la gente de los campos, a la deriva y decadencia del régimen oligárquico colonial y del primer siglo de República, y forjaron la idea de un país industrial y urbano-metropolitano; así fue hasta los 70. Luego, la globalización, la innovación, el capitalismo del conocimiento, etc., y el sueño viró tras ellos. Pero resulta que al final del ciclo, Chile sigue siendo esencialmente agrominero, como en los $50^{19}$.

Demográficamente hemos intentado mostrar la permanencia y hasta refundación de este patrón de poblamiento chileno, que no calza ni con el prejuicio ni con el concepto de lo rural, aunque lo incluye, y que deja la pregunta por el modo en que la sociedad chilena se relaciona con sus diversidades socio-productivas y territoriales.

Acaso lo contraintuitiva que resulta la fórmula agro-urbano, o ciudad agraria, como antes la agro-industria, sea la base de la no visualización social de este proceso de reconfiguración de la geografía humana chilena del último medio siglo. Es la confirmación del paisaje, no solo productivo, sino también demográfico, el que caracterizaba la sociedad chilena antes de la modernidad, y que la sigue caracterizando ahora, galopando en la era global.

Acaso el nuevo número que aquí se constata presione para que se reconozca la nueva socionimia (agraria, no solo rurales) que aquí se propone, y regresen las viejas toponimias agrícolas chilenas que, eppure, donde estaban, siguen estando.

De nuevo: la provincia y las comarcas inter-comunales, que llevan a las metrópolis treinta años de delantera en la globalización y la innovación, y por donde ha pasado el flujo de crecimiento poblacional más importante de estos nuevos tiempos.

19. Al respecto, véase Cerón, D., Cachapoal, provincia agrícola-minera, Tesis de Licenciatura en Historia y Geografía, Santiago: Universidad de Chile, 1948. Aquí ya se indica la forma misma que ahora, después de sesenta años de progreso formidable, según se estima local -y hasta globalmente-, volvemos a constatar. 


\section{REFERENCIAS BIBLIOGRÁFICAS}

Apey, A., Barril, A. (eds.), Pequeña agricultura en Chile. Rasgos socioproductivos, institucionalidad y clasificación territorial para la innovación, IICA, ODEPA, 2006.

Barrera, E., Turismo rural: nueva ruralidad y empleo rural no agrícola, Montevideo: CINTERFOR/ OIT, 2006.

Berdegué, J., Jara, B., Fuentealba, R., Tohá, J., Modrego, F, Schejtman, A., y Bro, N., Territorios funcionales en Chile, Documento de Trabajo, No 102, Programa Dinámicas Territoriales Rurales, RIMISP, Santiago de Chile, $2011^{\text {a }}$.

Berdegué, J., Jara, E., Modrego, F., Sanclemente, X., Schejtman, A., "Ciudades Rurales en Chile", en Revista paraguaya de sociología, No 138, Centro Paraguayo de Estudios Sociológicos, $2011 b$.

Canales, M., "Agrópolis-metrópolis. Más allá de lo rural y lo urbano", en Congreso de Desarrollo Rural, IICA, 2008, Santiago Chile, 2008, véase online en www.IICA.cl

Canales, M., Hernández, M.C., "Del fundo al mundo. Cachapoal, un caso de globalización agropolitana"', en Espacio abierto: Cuaderno venezolano de sociología, Vol. 20, No 4, octubre-diciembre 2011, págs. 579-605

Canales, M., Hernández, M., "Nueva agricultura y geografía humana. Refundación y dinamismo de las agro-urbes", en Revista paraguaya de sociología, № 138, Centro Paraguayo de Estudios Sociológicos, 2011b.

Canales, A. I., "Flexibilidad laboral y feminización del empleo en el agro chileno. Un caso más de desarrollo sin equidad", en Revista de economía y trabajo, No 11, Programa de Economía del Trabajo, Santiago de Chile, 2001, págs. 87-112.

- "Cambio agrario y poblamiento regional en Chile", en Estudios demográficos y urbanos, 31, Vol. 11, Nº1, México, El Colegio de México, enero-abril 1996, págs. 173 - 196.

- Cambio agrario y poblamiento regional en Chile, 1952 - 1986. El caso de la VI Región, Tesis de Doctorado, Centro de Estudios Demográficos y Urbanos, El Colegio de México, 1995.

Cerón, D., Cachapoal, provincia agrícola-minera, Tesis de Licenciatura en Historia y Geografía, Santiago: Universidad de Chile, 1948.

Gómez, S., "Reflexiones sobre la nueva ruralidad en América Latina", en Revista paraguaya de sociología, Nº 138, Centro Paraguayo de Estudios Sociológicos, 2011.

— La nueva ruralidad. ¿Qué tan nueva? (Revisión bibliográfica, un intento por definir su alcance y propuesta conceptual para investigaciones), 2da. edición ampliada, Santiago de Chile: Grupo de Investigaciones Agrarias y Universidad Academia de Humanismo Cristiano, 2008

Hoggart, K., Paniagua, A., "Rural Restructuring in Spain?", en Journal of Rural Studies, 17/1, 2001.

Kay, C., "Estudios rurales en América Latina en el periodo de globalización neoliberal: ¿una nueva ruralidad?", en Revista mexicana de sociología, Vol. 71, № 4, 2009.

Klein, E., El empleo rural no agrícola en América Latina, Documento de trabajo, № 364, Programa Regional de Empleo para América Latina y el Caribe, Santiago de Chile: OIT, 1992.

Nogue, J., "El fenómeno neo-rural", en Agricultura y sociedad, № 47, Madrid, 1988.

Pérez, E., "Hacia una nueva visión de lo rural", en Giarracca, N. (comp.), ¿Una nueva ruralidad en América Latina?, Buenos Aires: CLACSO, Grupo de Trabajo de Desarrollo Rural, 2001.

Pérez, E., Farah, M.A. y Grammont, H. de C. (comps.), La nueva ruralidad en América Latina: avance teóricos y evidencias empíricas, Bogotá: Pontificia Universidad Javeriana, 2008.

Philips, M., "Making Space for Rural Gentrification", en II Simposio Anglo- Español de Geografía Rural, España, Universidad de Valladolid, 2000. 
PNUD, Desarrollo Humano en Chile Rural. Seis millones por nuevos caminos, Santiago de Chile: PNUD, 2008.

Rodríguez, A., Saborío, M., y Candia, D., "Elementos para una mejor medición de lo rural en América Latina", en Revista paraguaya de sociología, No 138, Centro Paraguayo de Estudios Sociológicos, 2011.

Teubal, M., "Globalización y sus efectos sobre las sociedades rurales de América latina", en Memoria de sesiones plenarias V Congreso Latinoamericano de sociología Rural, ALASRU, Texcoco, México: Universidad Autónoma de Chapingo, 1998.

Venegas, S., "Las temporeras de la fruta en Chile", en Valdés, X., Arteaga, A.M. y Arteaga, C., (eds.), Mujeres. Relaciones de género en la agricultura, Centro de Estudios para el Desarrollo de la Mujer, Chile, 1995. 